\title{
ECONOMIC EFFICIENCY OF MERGERS IN THE CZECH REPUBLIC 2001-2010
}

\author{
Jaroslav SEDLÁČEK, Petr VALOUCH, Maria KRÁLOVÁ \\ Faculty of Economics and Administration, Masaryk University, \\ Lipová 41a, 60200 Brno, Czech Republic
}

Received 24 October 2012; accepted 01 June 2013

\begin{abstract}
The paper presents partial results of research focusing on accounting, taxation and legal aspects of mergers in the Czech market. The input source is a database of mergers implemented in the Czech territory, which compiles data taken from the Trade Register for the decade of 2001-2010. The structure of the data allows for an evaluation of development trends of mergers in the Czech market, analysis of economic consequences of mergers and finding possible causes of their success or failure. From economic characteristics of merger success, we have chosen the item of net assets. Statistical testing of the hypothesis proved that mergers do not affect net assets during the period of three years after the merger implementation. A significant dependence of net assets development on mergers was proved after the basic set was stratified based on the size of companies. Mergers have a positive effect on the growth of value for owners in the group of small enterprises in the third year after the merger; the value in the group of medium enterprises also grows, but not significantly. Regarding large enterprises, the net assets even decreased in consequence of a merger.
\end{abstract}

Keywords: company transformations, mergers and acquisitions, macroeconomic environment, economic effects of mergers, net assets, statistical analysis.

Reference to this paper should be made as follows: Sedláček, J.; Valouch, P.; Králová, M. 2013. Economic efficiency of mergers in the Czech Republic 2001-2010, Technological and Economic Development of Economy 19(Supplement 1): S326-S341.

JEL Classification: D22, G34, L21, M21.

\section{Introduction}

Company transformations are used today as strategic management instruments to stabilize the financial position and enhance financial performance. They are carried out either in the form of an internal (organizational) company growth, such as reinvestments of incomes, building of new plants, implementation of advanced technologies, etc., or they are of an

Corresponding author Jaroslav Sedláček

E-mail: sedl@econ.muni.cz 
external character - an enterprise joins another or is divided into more companies. The first references to mergers and acquisitions were observed at the end of the $19^{\text {th }}$ century, when in the USA there was a need for larger investments in business and an effort to stabilize the position of some enterprises in the market. Company combinations referred to as mergers and acquisitions (M\&A) lead to a concentration of capital accompanied by a creation of a stronger economic group; the ownership structure changes, new organizational systems and various projects in the personnel policy are created and developed, global company culture and company philosophy are born (Brealey et al. 2006). The study into the historical development of company combinations, has proven that activities in the M\&A market did not happen evenly but they fluctuated in dependence on the level of the economic environment, the development of financial markets and mainly the ideas of bidders and target businesses about the price of a takeover. Some authors in this respect use the term merger and acquisition waves - these waves come at a certain level of development of an economy. E.g. Levy, Sarnat (1999) talk about 3 waves, Bobenic-Hintos (2009) mentions 4 waves, Bruner (2004) divides the fourth wave into two: a) and b), Martynova, Rennebook (2008) differentiate 5 waves, Lipton (2011) identifies 6 waves of mergers and acquisitions that represent a considerable deviation from the gradually growing trend of global mergers and acquisitions:

Wave 1: 1893-1904

The first wave was characterized by horizontal combinations of companies, in which companies in the same fields of business merged. Their purpose was to reach a higher market share and the effort to monopolize the fields (raw material extraction, metallurgy, engineering, transport, car production and telecommunication). The wave started to drop when antitrust regulations became effective.

Wave 2: 1919-1929

In the second wave vertical combinations took hold, through which a bidder expands the company backwards, back to the sources of raw material, or forwards, towards the consumer. Due to the tightening of antitrust regulations, the interest shifted towards oligopolies. The wave coincided with the boom in US stock market prices and ended with the Wall Street Crash and the following economic recession.

Wave 3: 1955-1969 (1973)

This period is characterized by the creation of conglomerates, which are formed by companies with activities in non-related fields. Entering new business fields was supported by the stronger US economy and bullish trends (bull market). The end of the wave was affected by the decline of conglomerates and the non-existent contributions expected from the diversification.

Wave 4: 1974-1980 (1989)

In the fourth wave, the decline of conglomerates continued and most of the implemented acquisitions had a character of a hostile takeover bid. Companies were purchased through financing by debt - leveraged buy-out - which brought about an increase in trades in markets with junk bonds. The target businesses used newly developed tactics to defend against the hostile takeovers. This wave penetrated the European market as late as at the end of 1980s in the form of cross-border horizontal mergers and acquisitions. Also speculators in stock markets profited from the business combinations as they were able to profit even if the mergers were finally not successful. 
Wave 5: 1993-2000

In the 1990s managers' and owners' conviction predominated that expansion of a company will strengthen its competitiveness and stability. Companies started to consider possible advantages of company combinations and stock markets and mergers expanded again. Strengthening of operations and obtaining new technologies was mainly manifested in industrial fields, telecommunications, media and entertainment sectors. Growth was also manifested in international acquisitions and mergers. The fifth wave ended when the internet bubble burst and big business financial scandals emerged.

Wave 6: 2003-2006

The impulse for the sixth and for now last wave was globalization, support from governments of some countries (e.g. France, Italy and Russia) to create strong national or global champions, the rise in commodity prices, availability of low-interest financing, hedge funds and other stockholders' activities. The huge growth of private capital funds was accompanied by an increase in purchases initiated by managers. The burst of real estate bubble in the USA and the beginning of the global mortgage and credit crisis can be considered the end of this wave (Bank of America 2007).

It seems that the length of M\&A waves is shortening; however, another wave could hardly follows the sixth wave immediately, especially because this period was affected by a financial crisis, which then grew into the global economic crisis (2007-2009). The development of transaction activities of companies in 2005-2010 is presented in Figure 1, comparing the numbers and volumes of transactions implemented in the Czech and the Lithuanian markets (UNCTAD 2011).

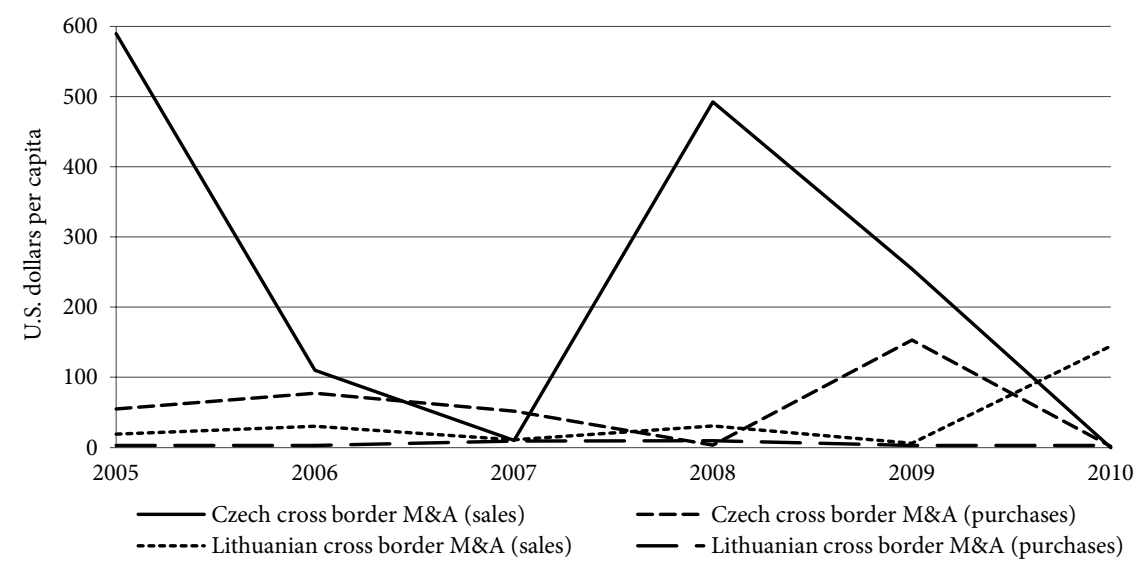

Fig. 1. Development of M\&A in the Czech Republic and Lithuania in the period 2005-2010

Figure 1 shows that investors' interest in buying companies in the Czech Republic exceeds the volumes of M\&A in the reverse direction, i.e. when the target company is located abroad, several times. Although volumes of foreign investments have a decreasing tendency during the monitored years, acquisitions reached a volume of nearly 500 USD/inhabitant in the Czech market in the period of the financial crisis (in 2008), in contrast to the macroeconomic situation. 
The Lithuanian market behaved similarly (Tvaronavičiene, Grybaite 2007; Stunguriene, Urbsiene 2011): also there the purchase in the period of crisis (2008) reached the same value as in the year before the crisis (2006). Higher trading volumes on the Czech market M\&A appears to be related to the attractiveness of the country for foreign investors. According to the evaluation carried out by the Research Centre of mergers and acquisitions in the Cass Business School in London reached the Czech market value of M\&A mathurity index 71\% and $59 \%$ of the Lithuanian market. Both economies are classified, as so-called transitive, between the developed and emerging countries. The development curves of real trades in the M\&A market as shown in Figure 1 do not present any signs of a new wave in 2006-2010.

On the activities in the markets of $M \& A$ acts in addition to macroeconomic conditions, a variety of factors (Zeng et al. 2012) caused the transformation of business motives. Trautwein (1990) in his publication defines seven theories of what motivates companies to combine within a process referred to as mergers and acquisitions (M\&A):

1. Efficiency theory, which is based on a synergic effect in the form of net profit;

2. Monopoly theory, which represents the achievement of a higher market power and leads to the transfer of wealth from customers;

3. Raider theory, according to which wealth is obtained from stockholders of the target business;

4. Valuation theory, which sees an information asymmetry as managers' advantage in negotiating the purchase price of the target business;

5. Empire-building theory, according to which managers maximize their utility at the expense of the shareholders' value. This approach has its roots in the separation of ownership from control in a company and the underlying idea is discussed in managerial theories of the firm;

6. Process theory considers the actual M\&A process to be of key importance for decision making which is not always completely rational. Cognitive simplification and other process factors can as a consequence affect mergers and acquisitions positively;

7. Disturbance theory considers mergers and acquisitions to be a macroeconomic phenomenon. According to this theory, activities in the M\&A field are influenced by disturbances in economy.

With the exception of the fifth theory, all these motivation theories lead to the achievement of a higher value for the owner of the successor company (investors). A typical manifestation of these motivation theories in practice is growth in business scale, expansion into adjacent business domains, acquisition of new technologies, restructuring of the existing business, diversification, conglomeration, or in a few cases, redefining the company's entire industry. History shows that in some periods external factors of company growth prevailed over the internal ones in dependence on the level of the economic environment and the development of financial markets, which motivated investors, owners and managers to perform company acquisitions and transformations (Gole, Hilger 2008; Hodes-Kropf, Viswanathan 2004).

Besides legal, accounting and taxation effects, our study focuses on the success rate of mergers; we investigate whether the owners' or the management's expectations were met or not. Partial results of the research into economic effects of mergers in the Czech environment are presented in this paper. 


\section{Methods}

Studies dealing with company transformations (Allen \& Overy 2011; Institute of Mergers, Acquisition and Alliances 2011), surveys conducted by audit firms of the Big Four [PricewaterhouseCoopers (PwC 2009), Deloitte \& Touche, Ernst \& Young, KPMG International (KPMG 2011)] or statistical data and database systems (UNCTAD 2011; Bloomberg 2011; Thomson Reuters 2011; Mergerstat 2013, etc.) do not distinguish mergers and acquisitions and simply use a collective term M\&A. However, there are substantial process differences between these two (legal, accounting, tax-related and social) that have economic impacts on the participating companies (Galiniené et al. 2006). An agreement on a combination of two or more enterprises into one, which thus gains more advantages than if the companies did business separately, is usually referred to as a merger. According to West's Encyclopedia of American Law (2011) a merger or acquisition is a combination of two companies where one corporation is completely absorbed by another corporation. The less important company loses its identity and becomes part of the more important corporation, which retains its identity. A merger extinguishes the merged corporation, and the surviving corporation assumes all the rights, privileges, and liabilities of the merged corporation. A merger is not the same as a consolidation, in which two corporations lose their separate identities and unite to form a completely new corporation (Nocke, Whinston 2013).

The Czech trade law defines a merger as a combination in which one or more companies cease to exist without liquidation and their equity, including rights and duties following from labour-law relations, are transferred to another existing or a newly established successor company. It means this is a legal combination which requires an agreement of all participating companies. On the other hand, an acquisition is a transaction in which one company (the bidder) gains a decisive share of the basic equity of another (target) business. The acquisition can have a character of a capital investment (capital acquisition) or a property acquisition, in which the entire company or its part is purchased. By this a group of companies connected by their capital arises and the legal position of individual companies does not change. Unless this is a hostile takeover, also a legal takeover can take place in case of property acquisition or capital acquisition by one owner. The differences between mergers and acquisition will mainly stand out in accounting procedures (Bohušová 2011; Malíková, Brabec 2012; Cassiman, Colombo 2006; Wirtz 2003). Similarly, the European law (Directive 2005/56/EC of the European Parliament and of the Council of 26 October 2005 on cross-border mergers of limited liability companies) defines a merger as a process in which one or more companies, on being dissolved without liquidation, transfer all their assets and liabilities to another existing or a new company, in exchange for the issue of securities or shares representing the capital of the successor company and, if applicable, a cash payment not exceeding $10 \%$ of the nominal value of those securities or shares.

When evaluating the economic success of M\&A, authors of the studies concentrate on the changes in the stock prices (e.g. Bayazitova et al. 2010; Teplý et al. 2010; Rosen 2006; Kling, Weitzel 2009) measured by the indicator of cumulative abnormal returns (CARs). Fritsch 2007 and Baker et al. (2012) expresses the economic efficiency of companies after the acquisition by the change in indicators return on equity (ROE) and cost to income ratio (CIR). Achampong, Zemedkun 1995 analyse the factors motivating managers to mergers using indicators such 
as the insider ownership ratio (IO), retained earnings ratio to net income (REI), the ratio of salary expenditures to total assets (S/TA) or the ratio of total operating expenditure to total assets (TOE/TA). Acquisitions are affected by the macroeconomic development more than mergers (Uygur et al. 2013). Turbulences at financial markets and their transfer to real economy are accompanied by decreasing liquidity and lower company profits (Sedláček 2007; Kiymaz 2013). Lack of capital hampers acquisitions, which are predominantly implemented in the form of cash flow. Neither of other forms financing like settlement by securities, bonds, or issuing new stocks are favourable for an acquisition implementation due to the decrease in prices. Regarding mergers, we can expect immunity against market turbulences as gained net assets are settled by transfers of ownership interest to successor companies. This is a barter transaction and its value can be affected by the market in the case of a publicly traded company. A drop or growth at financial markets can be indirectly reflected in valuation of mergers of non-traded companies as well. However, comparing the development of activities in the field of mergers only (without acquisitions) with activities at the market of both forms of company combinations (M\&A), we have to expect a different development (a zero correlation between the two development directions).

To be able to distinguish mergers from acquisitions in the conditions of the Czech economy, it was necessary to create a database which contained all mergers implemented in the monitored period (domestic and cross-border). The basic dataset included all company transformations from which one continuing company (successor) remained and one or more of the participating entities ceased to exist (company acquired). The initial source of data was the Trade Register (2011), from which the identification data of merging companies were excerpted as well as temporal, legal and economic information. The dataset in our database suitable for the analysis of economic effects comprises the period of one year before a merger (the situation of the last day before the decisive day) for all companies and then the situation at the end of each year for the period of 3 years after a merger for successor companies. The overview of the data extracted from financial statements of companies participating in mergers is presented in Table 1.

Table 1. The overview of data extracted from financial statements of companies in the monitored period

\begin{tabular}{lcl}
\hline Item in the statement & Abbrv. & Effect on company economy \\
\hline $\begin{array}{l}\text { Total assets of the } \\
\text { company }\end{array}$ & A & $\begin{array}{l}\text { High demands as concerns assets decrease the business } \\
\text { profitability and increase the indicator of total indebtedness. }\end{array}$ \\
\hline Net assets & NA & $\begin{array}{l}\text { Increase in net assets of a company means an increase in its } \\
\text { (accounting) value for owners. }\end{array}$ \\
\hline $\begin{array}{l}\text { Retained earnings } \\
\text { from past years }\end{array}$ & RE & $\begin{array}{l}\text { Retaining earnings in the company means creation of sources } \\
\text { for future investments. Support for company and management } \\
\text { development from owners. }\end{array}$ \\
\hline Earnings after taxes & EAT & Disposable profit created in the past economic year. \\
\hline $\begin{array}{l}\text { Added accounting } \\
\text { value }\end{array}$ & AAV & $\begin{array}{l}\text { Contains the business margin and the difference between sales } \\
\text { of products and services and their expenses. }\end{array}$ \\
\hline Personal costs & PC & $\begin{array}{l}\text { Higher incomes increase the operating costs, which are limited } \\
\text { by the rate of increase in company sales. }\end{array}$ \\
\hline $\begin{array}{l}\text { Earnings before } \\
\text { interest and taxes }\end{array}$ & EBIT & $\begin{array}{l}\text { Expresses the productive power of the company. A higher } \\
\text { profitability of total assets generates a higher value for owners. }\end{array}$ \\
\hline
\end{tabular}


The database includes all domestic mergers, as defined by the Czech Act on transformations (Act 2008) implemented in 2001-2010, in which the companies being dissolved go to an existing or a newly established (successor) company. In total, there are 360 successor companies whose financial statements were published in digital form in the Trade Register. The merger process is usually divided into three stages:

1. selection of and gaining knowledge about the partner, including a preliminary evaluation of the company being gained;

2. negotiations, due diligence, merger agreement (merger project);

3. implementation and integration.

While the first two stages take a relatively short time (several months), the third stage represents a demanding and often very lengthy integration of the merging companies aimed at the expected synergic effects. The realization of synergies heavily depends on how the differing organizational cultures of both partners will be respected and harmonized, what their cooperation will be like, their communication and conflict resolution, flexibility to changes, readiness to look for innovative solutions, etc. Statistics show that $54-90 \%$ of implemented transactions did not reach the expected effects or failed. According to study KPMG (2011), which summarizes results of mergers of its clients within the past 12 years, $17-34 \%$ transactions were able to increase the value after combination for company owners, in the other implemented transactions the economic effect did not take place or the company value even dropped. Many authors state (Bruner 2004; Picot 2008) that in the first two years after the agreement is concluded, the economic situation of the successor company deteriorates until the moment when a new complex management system of the transformed company is implemented and verified. Our partial study showed that the real proportion of unsuccessful mergers in all implemented Czech mergers in 2005-2008 can be expected to be within 55-68\% with 95\% reliability (Sedláček, Kuhrová 2012).

For a more detailed analysis we have chosen the net assets (NA) from Table 1 - these express the value for company owners. We expect that in the third year after the merger, the transformation should bring owners a higher value. All the below mentioned tests of hypotheses will be conducted at significance level $\alpha=0.05$, i.e. $p$-values lower than $5 \%$ will be interpreted as significant. Testing will proceed in three stages:

- at the $1^{\text {st }}$ stage we will test whether the merger increased the value of net assets (regardless of the size of companies);

- at the $2^{\text {nd }}$ stage we will test whether the size of companies affects the merger effect on the value of net assets;

- at the $3^{\text {rd }}$ stage we will test whether the merger increased the value of net assets, separately for small, medium and large companies (it means the test will be performed in strata based on size).

For this purpose we will introduce a new difference variable $N A a-N A b$, where $N A a$ stands for net assets of the successor company three years after the merger and $N A b$ stands for net assets of all participating companies before the merger. 


\section{Results}

\subsection{The first stage of hypothesis testing}

If a merger increases the value of net assets, we can expect that the sample will be dominated by positive differences.

Table 2. Descriptive statistics of the net assets sample

\begin{tabular}{lccccccccc}
\hline \multirow{2}{*}{ Variable } & \multicolumn{10}{c}{ Excluded outlier: 43 } \\
\cline { 2 - 11 } & $\begin{array}{c}\text { Nof } \\
\text { valid }\end{array}$ & Mean & Median & Minimum & Maximum & $\begin{array}{c}\text { Lower } \\
\text { quartile }\end{array}$ & $\begin{array}{c}\text { Upper } \\
\text { quartile }\end{array}$ & $\begin{array}{c}\text { Interquartile } \\
\text { range }\end{array}$ & $\begin{array}{c}\text { Standard } \\
\text { deviation }\end{array}$ \\
\hline$N A b$ & 313 & 872636.8 & 128589.0 & -1357759 & 39920497 & 30406.0 & 386665.0 & 356259.0 & 3105136 \\
\hline$N A a$ & 311 & 780519.7 & 118316.0 & -2061025 & 24486837 & 30209.0 & 374304.0 & 344095.0 & 2649966 \\
\hline$N A a-N A b$ & 311 & -96815.0 & 1357.0 & -15433660 & 14736568 & -67499.0 & 51351.0 & 118850.0 & 1993419 \\
\hline
\end{tabular}

As the descriptive statistics show (Table 2), the sample mean and the sample median of net assets $N A a$ decreased three years after the merger when compared with $N A b$ values before the merger. Also the mean of $N A a-N A b$ differences is negative but the median of differences is positive. The expected positive effect of a merger on the increase in assets does not correspond with the data. This fact needs to be tested. Due to the rough breach of normal distribution, parametric $t$-test cannot be used but the prerequisites for the paired Wilcoxon test are met. The hypothesis formulation follows:

- $\mathrm{H}_{0}$ the merger has no effect on the value of assets $N A$; population median of $N A a-N A b=0 ;(1)$

- $\mathrm{H}_{1}$ assets $N A$ are greater after the merger; $0<$ population median of $N A a-N A b$; (2)

- underlying assumption of continuous distribution is met;

- assumption of symmetric distribution around the median is also met as shown by histogram in Figure 2.

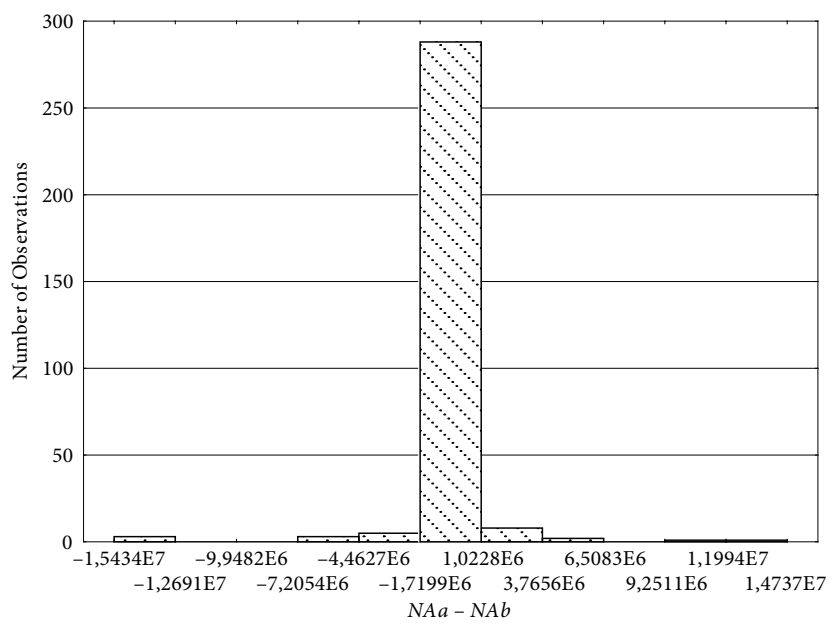

Fig. 2. Histogram $N A a-N A b$ for all participating companies (2001-2009) 
Wilcoxon test results are summarized in Table 3, where the p-value 0.986175 in the output corresponds to the two-tailed test. However, the p-value for the right-tailed test is $1-\mathrm{p} / 2=0.5069125>0.05$. The test has not proved at $5 \%$ significance level that a merger increases the value of net assets. We cannot state that a merger has a positive effect on the growth of owners' wealth.

Table 3. Wilcoxon paired test at significance level $\mathrm{p}<0.05$

\begin{tabular}{ccccc}
\hline \multicolumn{5}{c}{ Excluded outlier: 43 } \\
\hline & N of valid & T & Z & p-value \\
\hline Difference $N A a-N A b$ & 311 & 24230.5 & 0.017328 & 0.986175 \\
\hline
\end{tabular}

It is also possible that the effect of a merger on net assets is influenced by the size of the merged company and its effect on net assets may play a positive role at least in one of the size categories. For this purpose, we will first test whether the size of a company affects the merger effect on the value of net assets $N A$.

\subsection{The second stage of hypothesis testing}

The companies were divided based on their size (measured by the volume of their assets) into three categories, as shown in Table 4. In contrast to the recommendations of the European Commission EC 800/2008 are borderline value of assets of businesses chosen with regard to equitable representation of businesses in each category. Thus we can find out whether the variable Size affects the merger effect on net assets.

Table 4. Categories of companies based on the volume of assets (mCZK)

\begin{tabular}{lccc}
\hline Category & Small & Medium & Large \\
\hline Volume of assets & $\leq 100$ & $\leq 500$ & $>500$ \\
\hline Number of mergers & 74 & 119 & 118 \\
\hline
\end{tabular}

The descriptive statistics summarized in Table 5 indicate that the median of $N A a-N A b$ differences of large companies has a sign different from the median of $N A a-N A b$ differences of medium and small companies. Statistical significance of this difference will be tested using non-parametric tests (Kruskal-Wallis test and median test) as the parametric ANOVA cannot be used. The table of descriptive statistics is supplemented by a box plot in Figure 3, showing that large companies have a larger variability than medium and small companies

Table 5. Descriptive statistics of the net assets difference $N A a-N A b$ by size categories

\begin{tabular}{lccccccc}
\hline \multicolumn{1}{c}{ Variable } & $\begin{array}{c}\mathrm{N} \\
\text { of valid }\end{array}$ & Mean & Median & Minimum & Maximum & $\begin{array}{c}\text { Interquartile } \\
\text { range }\end{array}$ & $\begin{array}{c}\text { Standard } \\
\text { deviation }\end{array}$ \\
\hline Difference $N A a-N A b$ (total) & 311 & -96815.0 & 1357.0 & -15433660 & 14736568 & 118850.0 & 1993419 \\
\hline Difference $N A a-N A b$ (small) & 74 & 16645.22 & 4136.0 & -93871 & 425236.0 & 13238.00 & 62596,20 \\
\hline Difference $N A a-N A b$ (medium) & 119 & 17184.91 & 7114.0 & -453978 & 550612.0 & 73650.00 & 119109,2 \\
\hline Difference $N A a-N A b$ (large) & 118 & -282934 & -104487.0 & -15433660 & 14736568 & 690889.0 & 3233513 \\
\hline
\end{tabular}




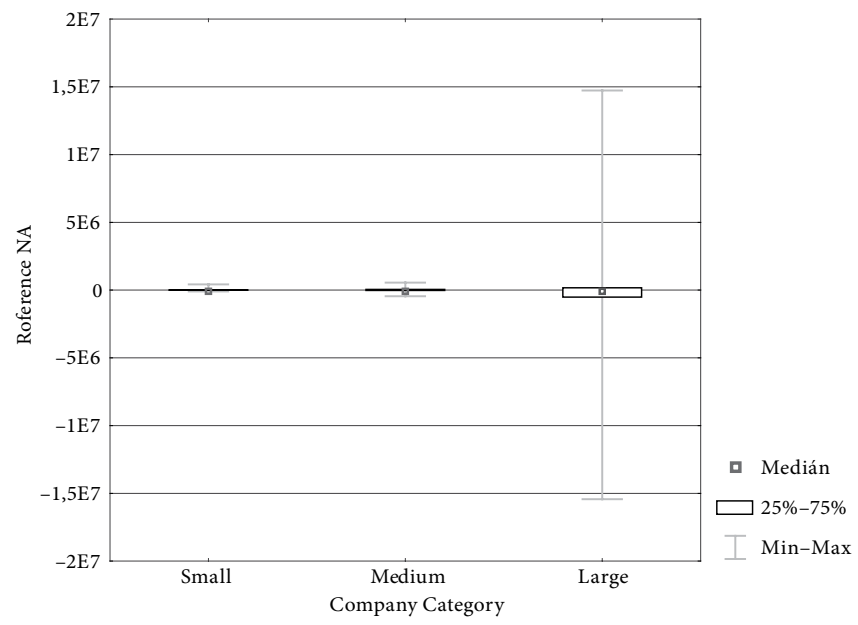

Fig. 3. Box plot of the difference of net assets before and after a merger $(N A a-N A b)$ by size

and that their results are the worst considering the mean and the median values of all the monitored size categories.

The Kruskal-Wallis test hypothesis is formulated as follows:

- $\mathrm{H}_{0}$ size does not affect the merger effect on $N A$; i.e. medians of $N A a-N A b$ in particular size categories are of the same value;

- $\mathrm{H}_{1}$ size of companies affects the merger effect on $N A$;

- underlying assumption of continuous distribution is met;

- the assumption of the same shape of histogram is not met completely, but results are relevant. The same conclusions will be reached by the median test which does not assume the same shape of histograms.

The results of the Kruskal-Wallis test based on ranks are summarized in Table 6. The value $\mathrm{p}=0.0144<0.05$ proves that the size of the company significantly affects the merger effect on net assets $N A$ of successor companies and the average ranking is the worst for large companies.

Table 6. Kruskal-Wallis test of NA difference based on ranks by size categories

\begin{tabular}{lcccc}
\hline & \multicolumn{4}{c}{ Independent (grouping) variable: size } \\
& K-W test ranking $\mathbf{H}(\mathbf{2} \mathbf{N}=\mathbf{3 1 1})=\mathbf{8 . 4 8 0 7 2 3 ;} \mathbf{p}=\mathbf{0 . 0 1 4 4}$ \\
\hline Dependent variable & Code & N of valid & Sum of ranks & Average ranks \\
\hline NA difference (small) & 1 & 74 & 12453.00 & 168.2838 \\
\hline NA difference (medium) & 2 & 119 & 19895.00 & 167.1849 \\
\hline NA difference (large) & 3 & 118 & 16168.00 & 137.0169 \\
\hline
\end{tabular}

The method of multiple comparison, will allow us to find out which size categories differ significantly. The test results summarized in Table 7 show a significant difference between the category of medium and the category of large companies $(p=0.029)$, while small and medium companies do not differ significantly ( $\mathrm{p}$-value $=0.057$ for comparison of large and small companies passed the $5 \%$ significance level only slightly). The differences between the 
categories indicate that large companies are in a worse situation than small and medium companies, which means that the increase in net assets after a merger has better values for medium and small companies.

Table 7. Multiple comparison method by categories

Multiple comparison of $\mathrm{p}$ values (two-tailed)
Independent (grouping) variable: size

Kruskal-Wallis test $\mathrm{H}(2, \mathrm{~N}=311)=8.480723 ; \mathrm{p}=0.0144$

\begin{tabular}{lccc}
\hline Dependent variable & Small (R: 168.28) & Medium (R: 167.18) & Large (R: 137.02) \\
\hline NA difference (small) & & 1.000000 & 0.057097 \\
\hline NA difference (medium) & 1.000000 & 0.029437 \\
\hline NA difference (large) & 0.057097 & 0.029437 & \\
\hline
\end{tabular}

The effect of the size of a company on the merger effect, i.e. the size of $N A$, will be verified by the median test:

- $\mathrm{H}_{0}$ the size does not affect the merger effect on $N A$; i.e. medians of $N A a-N A b$ in particular size categories are of the same value;

- $\mathrm{H}_{1}$ the size affects the merger effect on $N A$.

The results of the median test of the $N A$ difference between and after a merger $N A a-N A b$ by size categories are presented in Table 8 . Value $\mathrm{p}=0.0206$ proves that the size of the company significantly affects the merger effect on the net assets of the successor company. The median test thus reached the same conclusion as the Kruskal-Wallis test.

Table 8. Median test of NA difference before and after the merger by size categories

\begin{tabular}{ccccc}
\hline & \multicolumn{4}{c}{$\begin{array}{c}\text { Median test, total median }=\mathbf{1 3 5 7 . 0 0} \\
\text { Independent (grouping) variable: size } \\
\text { Chi-square = 7.768103; df = 2 p = 0.0206 }\end{array}$} \\
\hline Dependent variable: NA difference & Small & Medium & Large & In total \\
\hline S Median: observed & 29.00000 & 57.0000 & 70.0000 & 156.0000 \\
\hline expected & 37.11897 & 59.6913 & 59.1897 & \\
\hline = observed - expected & -8.11897 & -2.6913 & 10.8103 & \\
\hline$>$ Median: observed & 45.00000 & 62.0000 & 48.0000 & 155.0000 \\
\hline expected & 36.88103 & 59.3087 & 58.8103 & \\
\hline = observed - expected & 8.11897 & 2.6913 & -10.8103 & \\
\hline Expected in total & 74.00000 & 119.0000 & 118.0000 & 311.0000 \\
\hline
\end{tabular}

\subsection{The third stage of hypothesis testing}

Now that the effect of size on the volume of net assets (NA) of companies in the third year after a merger has been proved, we shall test whether a merger increases the owners' wealth. This time the test will be performed for each size category separately. Because the assumption of one-dimensional normal distribution is breached in all size categories, we cannot use paired $t$-tests. Neither usage of non-parametric paired Wilcoxon test in any of the categories is correct as all the three selections (by size) are non-symmetric based on medians. Therefore, it is 
necessary to use the sing test, whose only assumption of underlying continuous distribution is met in each of the size categories. The following hypothesis formulation is the same for each category: small, medium and large companies:

- $\mathrm{H}_{0}$ the merger has no effect on $N A$; population median of $N A b-N A a=0$;

- $\mathrm{H}_{1} N A$ are larger after the merger; population median of $N A a-N A b>0$.

The following tables show significant $\mathrm{p}$-values for the two-tailed alternative of large and small companies; only in medium companies mergers have no effect on NA. However, we are interested in p-values for right-tailed tests, which will be calculated as follows with respect to the values of testing statistics (percentage of $N A a<N A b$ ).

For large companies (Table 9) 70 values are located on the left from zero and 48 values on the right (inequality $N A a<N a b$ is valid for $59.32 \%$ ), it means the data are against the direction of the alternative and one-tailed $p=1-0.053211 / 2=0.973$. We have not proved that a merger leads to owners' wealth increase in large companies.

Table 9. The sign test for the category of large companies at $\mathrm{p}<0.05$ significance level

\begin{tabular}{lcccc}
\hline \multicolumn{4}{c}{ p-value for two-tailed test } \\
\hline Couple of variables & N of valid & Percentage $N A a<N A b$ & $\mathrm{Z}$ & $\mathrm{p}$-value \\
\hline Difference NA \& NA & 118 & 59.32203 & 1.933207 & 0.053211 \\
\hline
\end{tabular}

The data are in the direction of the alternative, but inconclusively, for medium companies (Table 10). Therefore, neither in the case of medium companies we can say that a merger leads to increased owners' wealth.

Table 10. The sign test for the category of medium companies at $\mathrm{p}<0.05$ significance level

\begin{tabular}{lcccc}
\hline \multicolumn{5}{c}{ p-value for two-tailed test } \\
\hline Couple of variables & N of valid & Percentage $N A a<N A b$ & $Z$ & p-value \\
\hline Difference NA \& NA & 119 & 47.05882 & 0.550019 & 0.582306 \\
\hline
\end{tabular}

As regards small companies (Table 11), there are 22 values on the left and 52 values on the right of zero, i.e. inequality $N A a>N A b$ is valid for $70.27027 \%$ of companies. The data are in the direction of the alternative and significantly because one-tailed $\mathrm{p}=0.000748 / 2=$ $0.000374<0.05$. A merger has increased the value of $N A$ statistically significantly and we can state that mergers lead to increased owners' wealth in the case of small companies.

Table 11. The sign test for the category of small companies at $\mathrm{p}<0.05$ significance level

\begin{tabular}{lcccc}
\hline \multicolumn{5}{c}{ p-value for two-tailed test } \\
\hline Couple of variables & N of valid & Percentage $N A a<N A b$ & $Z$ & p-value \\
\hline Difference NA \& NA & 74 & 29.72973 & 3.371182 & 0.000748 \\
\hline
\end{tabular}

We have proved that only in the case of small companies NA significantly increased 3 years after a merger. An increase also occurred in medium companies but not significantly; the merger effect on large companies was even a decrease in NA. Should the value of net assets $N A$ be the indicator of merger efficiency, mergers can be recommended to small companies, although still cannot imagine precisely identify the causes of this phenomenon. We assume that this is easier and faster implementation and integration of the merging of small businesses in the new conditions. 


\section{Discussion and conclusions}

The cornerstone for research into mergers in the Czech environment is the creation of a database of mergers implemented during past ten years. The structure of the extracted data not only enabled us to analyse the development of transformation activities in the Czech merger market (Sedláček et al. 2011, 2012; Valouch, Konečný 2011), but also provided the data for an empirical evaluation of economic effects of mergers. Analogically to published studies Fritsch (2007), Achampong, Zemedkun (1995), Sedláček, Kuhrová (2012), the obtained data can be used for an establishment of suitable financial analysis indicators, such as Return on Assets, Return on Equity, Retained Earnings Ratio to net Income, the Ratio of Salary Expenditures to Total Assets, Debt Ratio, Equity Ratio, etc. We base our study on the Efficiency and Process theory by Trautwein (1990), based on which a merger should bring a synergic effect in the form of increased profits. In a wider concept, this is an increase in the value of net assets of the company after a merger. However, the realization of the synergies is dependent on the way of respecting and harmonizing differing organizational cultures of the partners, their cooperation, communication and conflict resolution, flexibility to changes, readiness to look for innovative solutions, etc. We agree with Picot (2008) and Bruner (2004) that in the first two years after a merger agreement, the economic situation of the successor company usually deteriorates until the moment of implementation and verification of a new complex management system of the transformed company. The time lag will probably depend on the difficulty of negotiations and possible complications during implementation and integration of the company being dissolved into the new fully functional unit. To confirm or reject a positive effect of mergers on company owners' wealth we chose the time three years after a merger and the value of net assets of the successor company was chosen as the dependent variable. The hypothesis testing has proved a positive effect of mergers for small companies only; in large companies even a decrease in the monitored variable has been found, probably caused by the requirements of mergers (administrative, organizational and technical). If owners really gain economic advantage by a merger will only be fully revealed when this is measured by relative indicators depending e.g. on the change in total assets of the company or disposable profit in the third year after a merger implementation.

\section{Acknowledgements}

The paper contains first results of project of Grant Agency CR no. 403/11/0447 “The Analysis of Taxation and Accounting Procedures during Mergers". The project solution, which will be conducted in 2011-2013, was entrusted to the team of the Department of Finance, Faculty of Economics and Administration, Masaryk University in Brno.

\section{References}

Achampong, F. K.; Zemedkun, W. 1995. An empirical and ethical analysis of factors motivating managers' merger decisions, Journal of Business Ethic 14(10): 855-865. http://dx.doi.org/10.1007/BF00872351

Allen \& Overy, 2011. The Allen \& Overy M\&A Index, Q4 2010 Insight Report, official site [online], [cited 15 May 2011]. 2010. Available from Internet: http://www.allenovery.com/AOWeb/binaries/60916.PDF 
Baker, M.; Pan, X.; Wurgler, J. 2012. The effect of reference point prices on mergers and acquisitions, Journal of Economics 106(1): 49-71.

Bank of America, Annual Report, official site [online], [cited 31 March 2012]. 2007. Available from Internet: http://investor.bankofamerica.com.

Bayazitova, D.; Kahl, M.; Valkanov, R. 2010. Which mergers destroy value? Only mega-mergers, official site [online], [cited 10 May 2011]. Available from Internet: http://ssrn.com/abstract=1502385

BLOOMBERG, Markets Report, official site [online], [cited 22 September 2011]. 2011. Available from Internet: http://www.bloomberg.com/markets/stocks

Bohušova, H. 2011. General Approach to the IFRS and US GAAP Convergence, Acta Universitatis Agriculturae et Silviculturae Mendelianae Brunensis LIX(4): 27-36.

Bobenič-Hintoš, A. 2009. Waves of mergers and acquisitions, Acta Oeconomica Cassoviensia 2(1): 13-21.

Brealey, R. A.; Myers, S. C.; Allen, F. 2006. Principles of corporate finance. 8th ed. Boston: McGraw-Hill. $1028 \mathrm{p}$.

Bruner, R. F. 2004. Applied mergers and acquisitions. Hoboken: John Wiley \& Sons Inc. 1029 p.

Cassiman, B.; Colombo, M. G. 2006. Mergers \& acquisitions: the innovation impact. Cheltenham: Edward Elgard. 200 p. http://dx.doi.org/10.4337/9781847201584

Fritsch, M. 2007. Long term effects of bank acquisitions in Central and Eastern Europe. Goethe University Frankfurt, Working Paper Series, official site [online], [cited 26 July 2012]. Available from Internet: http://papers.ssrn.com/sol3/results.cfm?RequestTimeout $=50000000$

Galiniene, B.; Marčinskas, A.; Malevskiene, S. 2006. The cycles of real estate market in the Baltic countries, Technological and Economic Development of Economy 12(2): 161-167.

Gole, W. J.; Hilger, P. J. 2008. Corporate divestitures: a mergers and acquisitions best practices guide. Hoboken: John Wiley \& Sons Inc. 299 p.

Hodes-Kropf, M.; Viswanathan, S. 2004. Market valuation and merger waves, The Journal of Finance 59(6): 2685-2718. http://dx.doi.org/10.1111/j.1540-6261.2004.00713.x

Institute of Mergers, Acquisition and Alliances (IMAA) 2011. Official site [online], [cited 26 July 2011]. Available from Internet: http://imaa-institute.org

Kiymaz, H. 2013. Cross-border mergers and acquisitions and country risk ratings: evidence from U.S. financials, The International Journal of Business and Finance Research 7(1): 17-29.

Kling, G.; Weitzel, U. 2009. Endogenous mergers: bidder momentum and market reaction, Applied financial Economics 20(3): 243-254. http://dx.doi.org/10.1080/09603100903282663

KPMG. 2011. A new dawn: good deals in challenging times, official site [online], [cited 27 November 2011]. Available from Internet: http://KPMG_MA-New-Dawn-2011.pdf

Levy, H.; Sarnat, M. 1999. Capital investment and financial decision. Prague: Grada Publishing. 920 p.

Lipton, M. 2011. Merger Waves in the 19th, 20th and 21st Centuries, York University: Osgoode Hall Law School, official site [online], [cited 11 May 2011]. Available from Internet: http://papers.ssrn.com/ sol3/papers.cfm?abstract_id $=966294$

Malíková, O.; Brabec, Z. 2012. The influence of a different accounting system on informative value of selected financial ratios, Technological and Economic Development of Economy 18(1): 149-163. http://dx.doi.org/10.3846/20294913.2012.661193

Martynova, M.; Rennebook, L. 2008. The performance of the European market for corporate control: evidence from the 5th takeover wave, Sheffield University: Management School official site [online], [cited 11 May 2011]. Available from Internet: http://ssrn.com/abstract=941731

Mergerstat. 2013. Factset mergers [online], [cited 19 December 2013]. Available from Internet: http://www.factset.com/data/factset_data/factsetmergers 
Nocke, V.; Whinston, M.D. 2013. Merger policy with merger choice, American Economic Review 103(2): 1006-1033. http://dx.doi.org/10.1257/aer.103.2.1006

Picot, G. 2008. Handbuch mergers and acquisitions, Stuttgard: Schäffer-Poeschel. 423 p.

PricewaterhouseCoopers International Limited (PwC). 2009. Eastern Approaches official site [online], [cited 28 July 2012]. Available from Internet: http://www.pwc.co.uk/en_UK/uk/assets/pdf/technologyma-insights-2009-1mb.pdf

Rosen, R. J. 2006. Merger momentum and investor sentiment: the stock market reaction to merger announcements, The Journal of Business 79(2): 1-38. http://dx.doi.org/10.1086/499146

Sedláček, J. 2007. Analysis of the financial burden of the Czech enterprises in period 1996 - 2005, Journal of Economics 55(6): 582-593.

Sedláček, J.; Konečný, A.; Valouch, P. 2011. Analysis of the financial crisis effect on company mergers, in Proceedings of the $10^{\text {th }}$ WSEAS International Conference on E-Activities (E-ACTIVITIES'2011). Jakarta: WSEAS, 106-111.

Sedláček, J.; Kuhrová, K. 2012. An analysis of unsuccessful mergers in the Czech environment, in Proceedings of the International Scientific Conference on European Financial Systems 2012. Brno: Masaryk University, 194-200.

Sedláček, J.; Valouch, P.; Hýblová, E. 2012. Developmental analysis of mergers in the Czech Republic in 2001-2009 from the perspective of ownership structure, in Recent Researches in Business and Economics - Proceedings of the $4^{\text {th }}$ WSEAS World Multiconference on Applied Economics, Business and Development (AEBD'12). Porto: WSEAS, 65-70.

Stungurienè, S.; Urbšienè, L. 2011. Assesment of construction object financing solutions, Technological and Economic Development of Economy 17(4): 579-594. http://dx.doi.org/10.3846/20294913.2011.580590

Teplý, P.; Stárová, H.; Černohorský, J. 2010. Value creation of european bank mergers and acquisitions in the 1998-2007 period, Journal of Economics 58(5): 458-470.

Thomson Reuters 2011. Official site [online], [cited 19 June 2011]. Available from Internet: http://graphicsthomsonreuters.com/11/04/M\&A_Summit.pdf

Trade Register, 2011. Official site [online], [cited 16 May 2012]. Available from Internet: http://ov.ihned. cz/index.php?p=302000

Trautwein, F. 1990. Merger motives and merger prescriptions, Strategy Management Journal 11(4): 283-295. http://dx.doi.org/10.1002/smj.4250110404

Tvaronavičiene, M.; Grybaite, V. 2007. Impact of FDI on Lithuanian economy: insight into development of main economic activities, Journal of Business Economics and Management 8(4): 285-290.

UNCTAD Handbook of Statistics. 2011. New York: UN Publications. 513 p.

Uygur, O.; Meric, G.; Meric, I. 2013. The financial characteristics of U.S. companies acquires by foreign companies, Global Journal of Business Research 7(1): 1-8.

Valouch, P.; Konečný, A. 2011. The development of the number and the structure of mergers of trading companies in the Czech Republic in 2001-2010, in The 6th IASME/WSEAS International Conference on Economy and Management Transformation (EMT '11). Angers, France: WSEAS Press, 25-30.

West's Encyclopedia of American Law, 2011. Official site [online], [cited 30 November 2011]. Available from Internet: http://answers.com/library/LawEncyclopedia-cid-3554923

Wirtz, B. W. 2003. Mergers \& acquisitions: Management: Strategie und Organisation Unternehmenszusammenschlüssen. Wiesbaden: Gabler. $521 \mathrm{p}$.

Zeng, R.; Zeng, S.; Xie, X.; Tam, Ch.; Wan, T. 2012. What motivates firms from emerging economies to go internationalization?, Technological and Economic Development of Economy 18(2): 280-298. http://dx.doi.org/10.3846/20294913.2012.677588

Act No. 125/2008 Coll., on transformations of trading companies and cooperatives. 
Jaroslav SEDLÁČEK. He is an Associate Professor at Masaryk University, Faculty of Economics and Administration, Department of Finance. He is the author of several monographs and articles in scientific journals and proceedings of international conferences. His scientific work is focused on the financial management of enterprises.

Peter VALOUCH. He is an Assistant Professor at Masaryk University, Faculty of Economics and Administration, Department of Finance. He publishes in scientific and professional journals, lectured at scientific conferences and is an author and co-author of technical books. He deals with the theory of financial accounting, financial analysis and taxation of individuals and business entities.

Maria KRÁLOVÁ. She is an Assistant Professor at Masaryk University, Faculty of Economics and Administration, Department of Statistics. She is the author of several textbooks, scientific and professional articles and papers in proceedings of international conferences. She deals with the mathematical and statistical methods in economics and financial sciences. 